\title{
CRESCIMENTO DE PLANTAS DE SOJA EM FUNÇÃO DE DOSES DE SULFENTRAZONE ${ }^{1}$
}

\author{
JOÃO S. ARRUDA ${ }^{2}$, NEI F. LOPES ${ }^{3}$ e MARCOS A. BACARIN ${ }^{4}$
}

\section{RESUMO}

O efeito de doses de sulfentrazone foi avaliado no crescimento da soja BR-16, inoculadas com estirpe SEMIA 5079, em condições de casa de vegetação. A fitotoxicidade do sulfentrazone aumentou com o incremento na dose do herbicida, nos estádios $\mathrm{V}_{2}$ e $\mathrm{R}_{5}$, agravando-se com o passar do tempo. $\mathrm{O}$ sulfentrazone reduziu a área foliar, o acúmulo de matéria seca total e dos órgãos, a altura da planta e o comprimento das raízes tanto no estádio $R_{3}$ quanto no $\mathrm{R}_{5}$. $\mathrm{O}$ crescimento das raízes foi mais afetado pelo sulfentrazone do que a parte aérea, sendo que a relação parte aérea/ raízes aumentou com o incremento na dose do herbicida. A cultivar de soja BR-16 apresentou baixa tolerância ao sulfentrazone, pois o herbicida influenciou negativamente todos os parâmetros analisados.

Palavras chaves: Glycine $\max$, fitotoxicidade, herbicida.

\section{ABSTRACT \\ Growth of soybean plants in function of sulfentrazone rates}

The effect of sulfentrazone rates was evaluated on growth of soybean cv. BR-16, inoculated with strain SEMIA 5079, under greenhouse conditions. The sulfentrazone phytotoxicity increased as herbicide rates enhanced at $V_{2}$ and $R_{5}$ stages, aggravating the damage with the time. Leaf area, organs and total dry matter accumulations, plant heigh and roots length were reducted by sulfentrazone at $\mathrm{R}_{3}$ and
$\mathrm{R}_{5}$ stages. The roots growth was more affected by sulfentrazone than shoot, occuring increment of shoot/roots ratio with augment on herbicide rates. The soybean cv. BR-16 showed low tolerance to sulfentrazone, based on the negative effect of the herbicide for all parameters studied. herbicide.

\section{INTRODUÇÃO}

A produtividade da cultura da soja está associada a fatores intrínsecos que interagem com o ambiente, como temperatura, umidade do solo, fotoperíodo e práticas culturais, que são elementos essenciais para a expressão máxima de rendimento. Dentre os tratos culturais, destaca-se

\footnotetext{
${ }^{1}$ Recebido para publicação em 07/08/98 e na forma revisada 05/01/99. Parte da dissertação do primeiro autor apresentada à UFPEL para obtenção do título de Mestre em Fisiologia Vegetal.

${ }^{2}$ Eng $^{\circ}$ Agr $^{\circ}$, M.Sc, Bolsista da Capes, Dept ${ }^{\circ}$ Botânica, Universidade Federal de Pelotas. C.P. 354, CEP: 96010-900, Pelotas/RS.

${ }^{3}$ Eng $^{\mathrm{o}}$ Agr $^{\mathrm{o}}$, Ph.D., Prof ${ }^{\mathrm{o}}$ Titular, Bolsista do CNPq, Dept ${ }^{\circ}$ Botânica, Universidade Federal de Pelotas. C.P. 354, CEP: 96010900, Pelotas/RS.

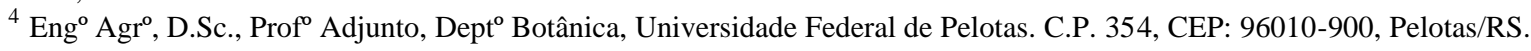


o uso de agroquímicos para o controle de ervas daninhas, que se desenvolvem junto a cultura. $\mathrm{O}$ emprego de herbicida tem crescido na ordem de $20 \%$ a cada ano, nas últimas décadas. O uso indiscriminado dos herbicidas pode causar injúrias para as plantas de soja, assim como malefícios para o meio ambiente. A efetividade dos herbicidas no controle de plantas daninhas em uma cultura é baseada primeiramente na seletividade interespecífica, mas a intraespecífica também pode existir, sendo que essas diferenças dentro da espécie podem resultar em severa e inesperada fitoxicidade ou em maior margem de segurança para a cultura (Wax, 1973).

O sulfentrazone é um herbicida recomendado para o controle das principais plantas daninhas da cultura da soja. Tem como mecanismo principal de ação o rompimento de membranas das plantas invasoras suscetíveis. Assim como outros herbicidas, o sulfentrazone pode apresentar uma baixa seletividade nas plantas de soja. Para que se possa avaliar esse efeito nas planta, faz-se necessário uma análise de crescimento, baseada no acúmulo de matéria seca de toda a planta e de suas partes como: caule, folhas, raízes, etc., a dimensão do aparelho assimilatório (área foliar). O padrão de distribuição de fotoassimilados entre os órgãos da planta é uma característica determinante da produção (Gifford et al. , 1984). A partição da biomassa em uma planta é controlada pela relação entre a fonte e o dreno. Essa relação pode ser influenciada pelo uso de agroquímicos.

Baseado no exposto se realizou esta pesquisa para verificar o efeito de diferentes doses do herbicida sulfentrazone no crescimento de plantas de soja.

\section{MATERIAL E MÉTODOS}

A fitoxicidade do herbicida sulfentrazone nas plantas de soja foi avaliado visualmente, com o emprego da escala E.W.R.C. (European Weed Research Council), aos 25 e 65 DAS, onde 1- sem efeito, 2- sintoma muito leve, 3- sintoma leve, 4sintomas não refletidos na produção, 5- médio, 6- dano regular, 7- dano forte, 8 - dano muito forte e 9- morte da planta.

As amostras foram colhidas nos estádios de desenvolvimento $R_{3}$ e $R_{5}$, ou seja, aos 58 e 65 dias após a semeadura das sementes (DAS). Em cada amostragem foi verificada a altura das plantas, medindo-se a distância do substrato até o ponto de inserção da gema apical. A seguir foi seccionada a parte áerea rente ao solo e separada em caule, pecíolo e lâmina foliar. $\mathrm{Na}$ amostra colhida aos 65 dias, também foi separada as vagens. Após a coleta do exsudato dos vasos do xilema, as raízes das plantas foram separadas do substrato por lavagem com água corrente em peneira. Em seguida foi medido o comprimento das raízes, e a área foliar.

Para a obtenção da matéria seca da parte aérea (Wpa), e de cada órgão e das raízes (Wr), o material foi colocado em estufa de ventilação forçada a $75 \pm 2^{\circ} \mathrm{C}$, por 72 horas, determinando-se a massa gravimetricamente.

Os resultados foram submetidos a análise de variância e aplicados testes de Duncan ( $\mathrm{P} \leq$ $0,05)$. Análises de regressões foram realizadas para obter as equações matemáticas que melhor se ajustassem aos dados experimentais da matéria seca total, da parte aérea, das raízes, área foliar, altura e comprimento das raízes. E, também foram calculados os índices que inibiram esses parâmetros em $50 \%$ ( $\left.\mathrm{I}_{50}\right)$, em função das diferentes doses do herbicida sulfentrazone.

\section{RESULTADOS E DISCUSSÃO}

A ação de injúria do sulfentrazone na parte aérea das plantas de soja aumentou com o incremento na dose do herbicida (Tabela 1), tanto aos 25 como aos 65 DAS. A fitotoxicidade foi menor aos 25 DAS, nesse estádio de crescimento $\left(\mathrm{V}_{2}\right)$ a plântula provavelmente, ainda, estava utilizando nutrientes via mobilização de reservas da semente para seu crescimento e manutenção. No momento em que as reservas da semente terminaram, a planta começou a utilizar os fotoassimilados produzidos pela planta e absorver sais minerais do solo. A partir desse momento a 
planta começou ter problemas fitotóxicos, em virtude do acúmulo do herbicida nas partes aéreas da planta. A translocação do sulfentrazone ocorre acropetamente via xilema e concentra-se nas folhas (Walker et al., 1992; Vidrine et al., 1994).

A fitotoxicidade causada pelo sulfentrazone nas diversas variedades de soja está intimamente relacionada com a rapidez com que o herbicida é metabolizado. Nas plantas tolerantes ocorre rápida degradação oxidativa do produto, como forma de detoxificação (El Naggar et al.,
1992), sendo essa realizada pela enzima peroxidase. O mecanismo de ação do sulfentrazone nas plantas suscetíveis esta relacionado com a inibição da enzima protoporfirinogênio oxidase (Protox) (Dayan et al., 1997). Em plantas de soja não tolerantes ao herbicida essa degradação oxidativa é inibida, quando essa inibição ocorre os tecidos sofrem oxidações, rompendo membranas, fenômeno esse chamado de estresse de peroxidase (Finck \& Kunert, 1985).

TABELA 1. Análise visual de fitotoxicidade das plantas de soja, aos 25 e 65 dia após a semeadura (DAS), valores expressos segundo a escala de E.W.R.C

\begin{tabular}{ccc}
\hline Fitotoxicidade & \multicolumn{2}{c}{ Dias após a semeadura } \\
\cline { 2 - 3 } Dose $\left(\mu \mathrm{g}\right.$ i.a. $\left.\mathrm{m}^{-2}\right)$ & $25\left(\mathrm{~V}_{2}\right)$ & $65\left(\mathrm{R}_{5}\right)$ \\
\hline 0 & 1 & 1 \\
36 & 1 & 2 \\
72 & 2 & 3 \\
108 & 3 & 5 \\
144 & 4 & 8 \\
\hline
\end{tabular}

A análise de fitotoxicidade mostrou que houve injúria drástica na parte aérea, que aumentou com o incremento na dose de sulfentrazone (Tabela 1), aos 25 e 65 DAS. Aos 25 DAS, o sulfentrazone na dose $36 \mu \mathrm{g}$ i.a. $\mathrm{m}^{-2}$ não mostrou fitotoxicidade e sintoma muito leve na dose $72 \mu \mathrm{g}$ i.a. $\mathrm{m}^{-2}$, apresentando fitotoxicidade com sintoma leve na dose $108 \mu \mathrm{g}$ i.a. $\mathrm{m}^{-2}$ e sintoma não refletido na produção na dose $144 \mu \mathrm{g}$ i.a $\mathrm{m}^{-2}$, acarretando prejuízo para o crescimento das plantas de soja. Enquanto, aos 65 DAS, o sulfentrazone na dose $36 \mu \mathrm{g}$ i.a $\mathrm{m}^{-2}$ mostrou sintoma muito leve e leve na dose $72 \mu \mathrm{g}$ i.a. $\mathrm{m}^{-2}$, apresentando sintomas médios na dose $108 \mu \mathrm{g}$ i.a $\mathrm{m}^{-2}$ e dano muito forte na $144 \mu \mathrm{g}$ i.a. $\mathrm{m}^{-2}$. Ficou evidente que o efeito fitotótoxico do herbicida sulfentrazone acentuouse com a idade das plantas de soja, no intervalo de tempo entre $V_{2}$ e $R_{5}$.

$A$ área foliar $\left(A_{f}\right)$ foi drasticamente reduzida com aumento nas doses de sulfentrazone tanto no estádio $\mathrm{R}_{3}(58 \mathrm{DAS})$ quanto $\mathrm{R}_{5}$ (65 DAS) (Figura 1A). As plantas controle apresentaram $A_{f}$ de 0,61 e $0,76 \mathrm{~m}^{-2} \cdot$ planta $^{-1}$, enquanto $A_{f}$ das tratadas com $72 \mu \mathrm{g}$ i.a. $\mathrm{m}^{-2}$ de sulfentrazone, dose recomendada para a aplicação na cultura da soja, foram de 0,29 e $0,45 \mathrm{~m}^{2}$. planta 1, ocorrendo uma redução de 52,4 e $40,0 \%$, respectivamente aos 58 e 65 DAS. Obviamente, o percentual de redução de $\mathrm{A}_{\mathrm{f}}$ foi bem maior em doses acima da recomendada $\left(>0,72 \mu \mathrm{g}\right.$ i.a. $\left.\mathrm{m}^{-2}\right)$, sendo que os valores de $A_{f}$ foram praticamente iguais nas duas doses mais elevadas do herbicida $\left(108\right.$ e $144 \mu \mathrm{g}$ i.a. $\left.\mathrm{m}^{-2}\right)$. As doses que inibiram $50 \%$ da área foliar $\left(\mathrm{I}_{50}\right)$, foram de 64,0 e $79,5 \mu$ gi.a. $\mathrm{m}^{-2}$ respectivamente, aos 58 e 65 DAS, ficando bastante próxima da dose recomendada (Figura 1B).

O sulfentrazone reduziu o tamanho do aparelho assimilatório, acarretando distúrbios funcionais no crescimento e desenvolvimento das plantas de soja, como redução na matéria seca total (Figura 4), no comprimento das raízes (Figura 5) e na altura das plantas (Figura 6). No estádio $\mathrm{R}_{5}$, aos $65 \mathrm{DAS}$, ocorreu uma queda acentuada em $A_{f}$ das plantas tratadas com sulfentrazone, em doses maiores de $36 \mu \mathrm{g}$ i.a. $\mathrm{m}^{-}$ 2. 

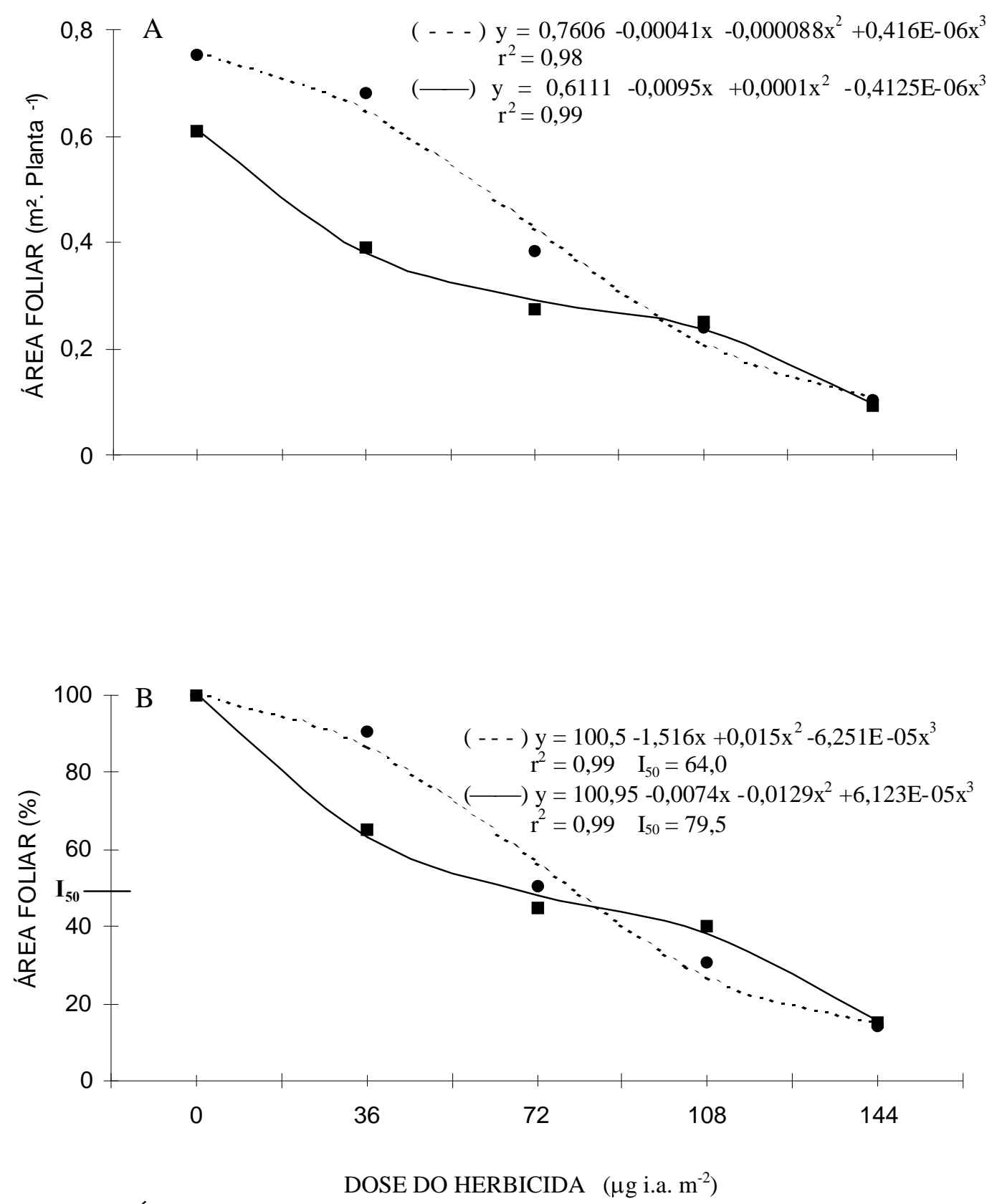

FIGURA 1. Área foliar de plantas de soja em função de doses de sulfentrazone, aos 58 aos $65(\bullet$ e - - - ) dias após a semeadura. 

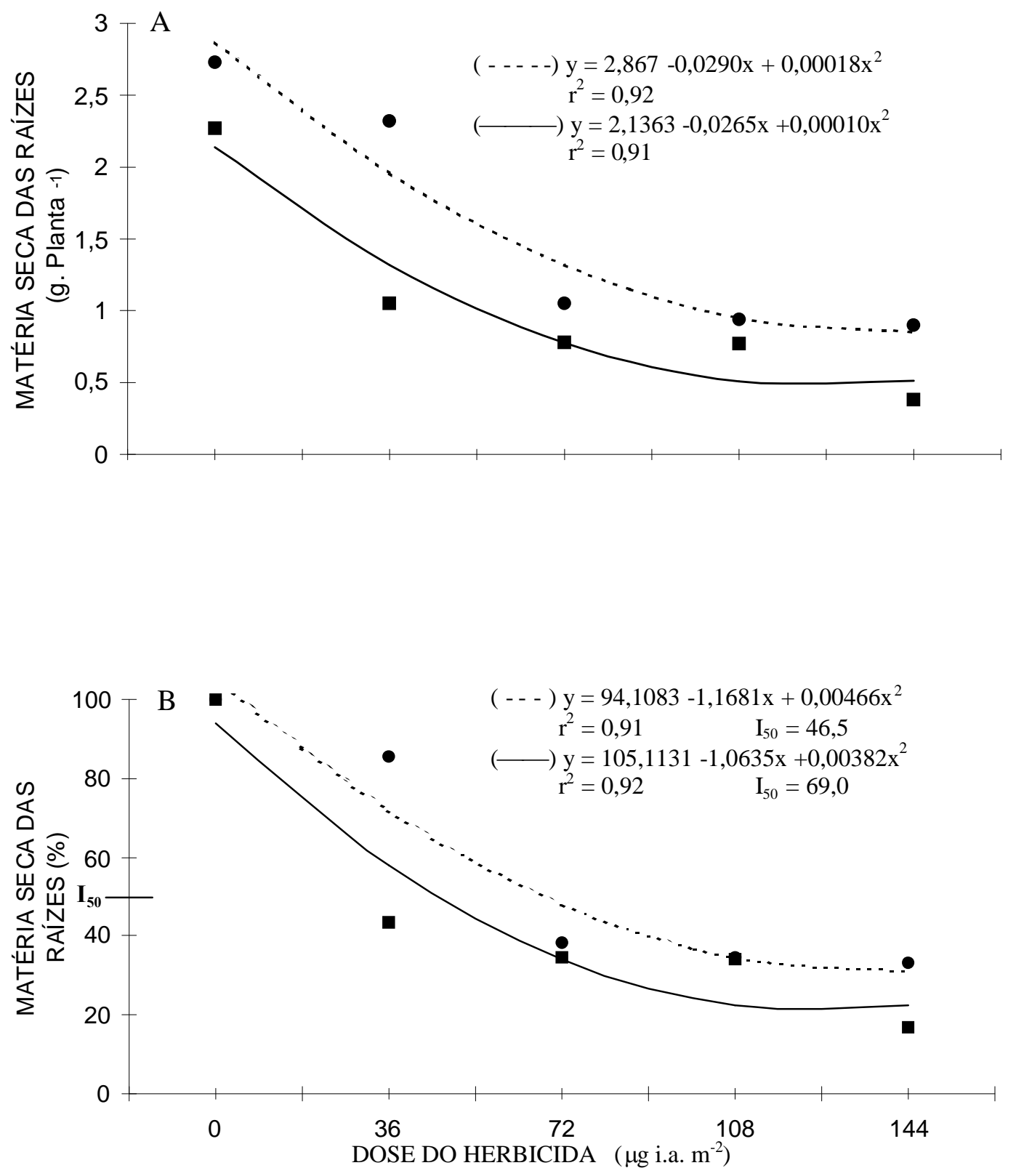

FIGURA 2. Matéria seca das raízes de plantas de soja em função das doses de sulfentrazone, aos 58 e ——) e aos 65 (• e - - - ) dias após a semeadura. 

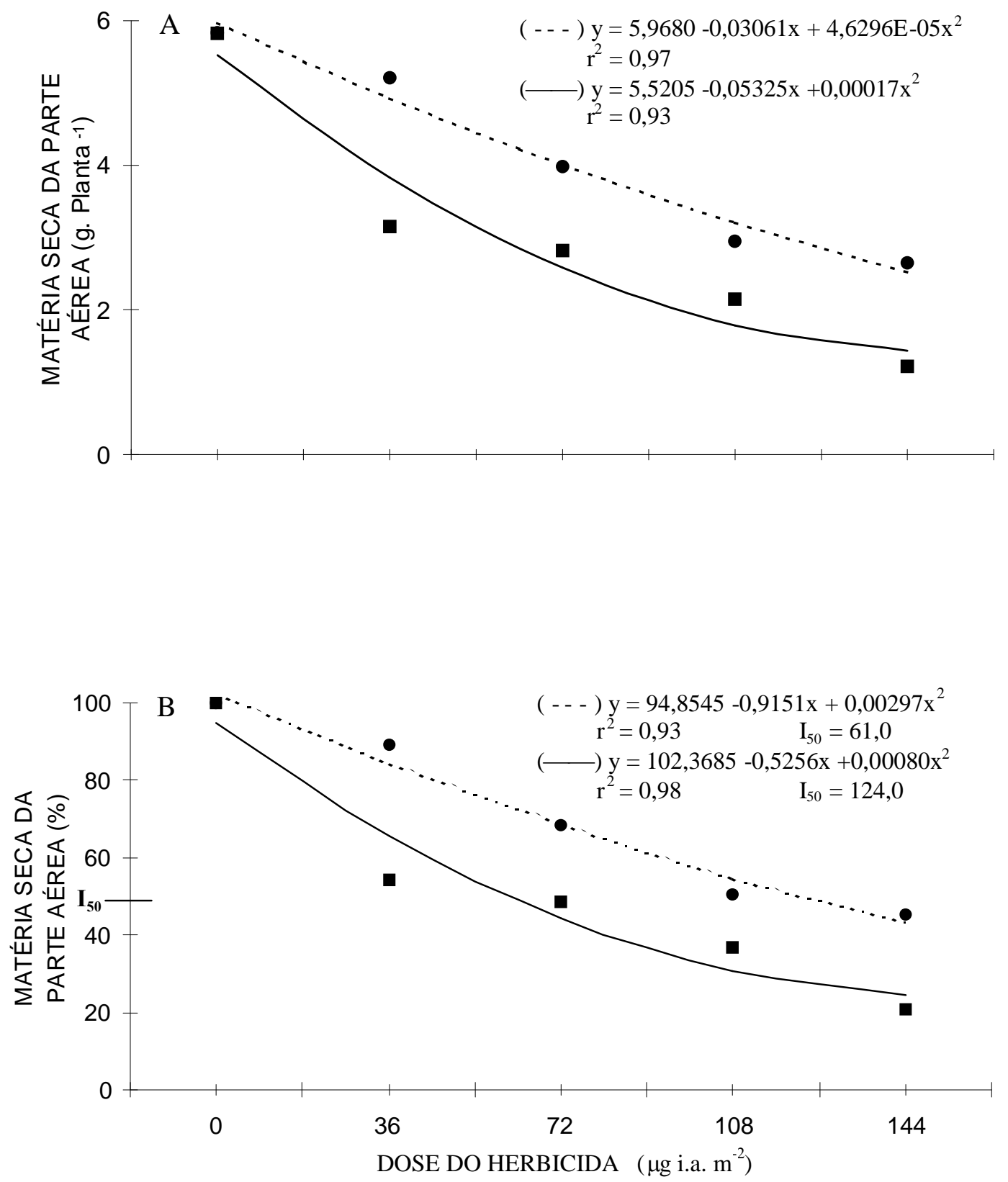

FIGURA 3. Matéria seca da parte aérea de plantas de soja em função de doses de sulfetrazone, aos 58 ( $\mathrm{e}-$ ) e aos 65 (๑ e - - - ) dias após a semeadura. 

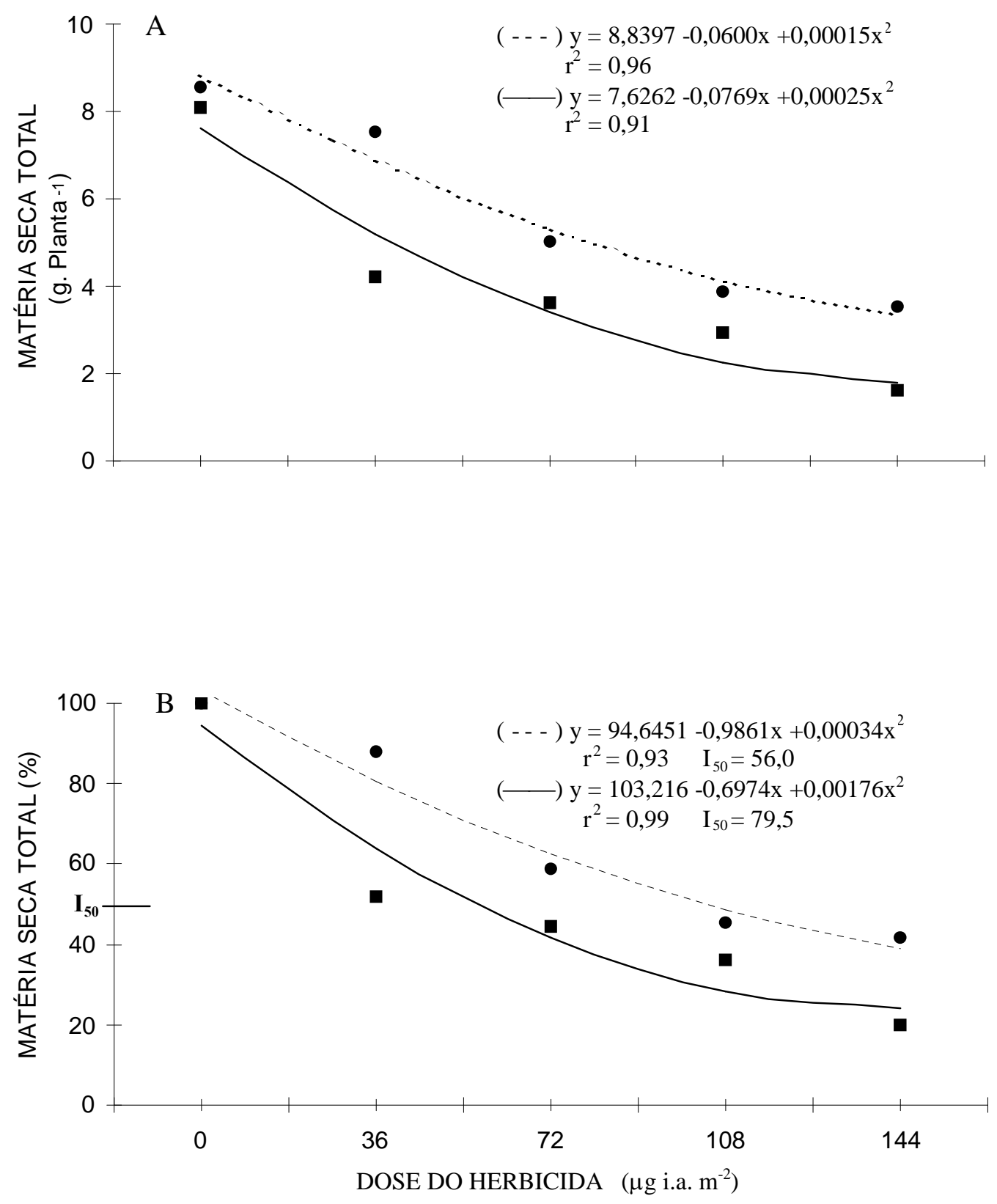

FIGURA 4. Matéria seca total das plantas de soja em função das doses de sulfetrazone, aos 58 - - ) e aos 65 (• e - - - ) dias após a semeadura. 

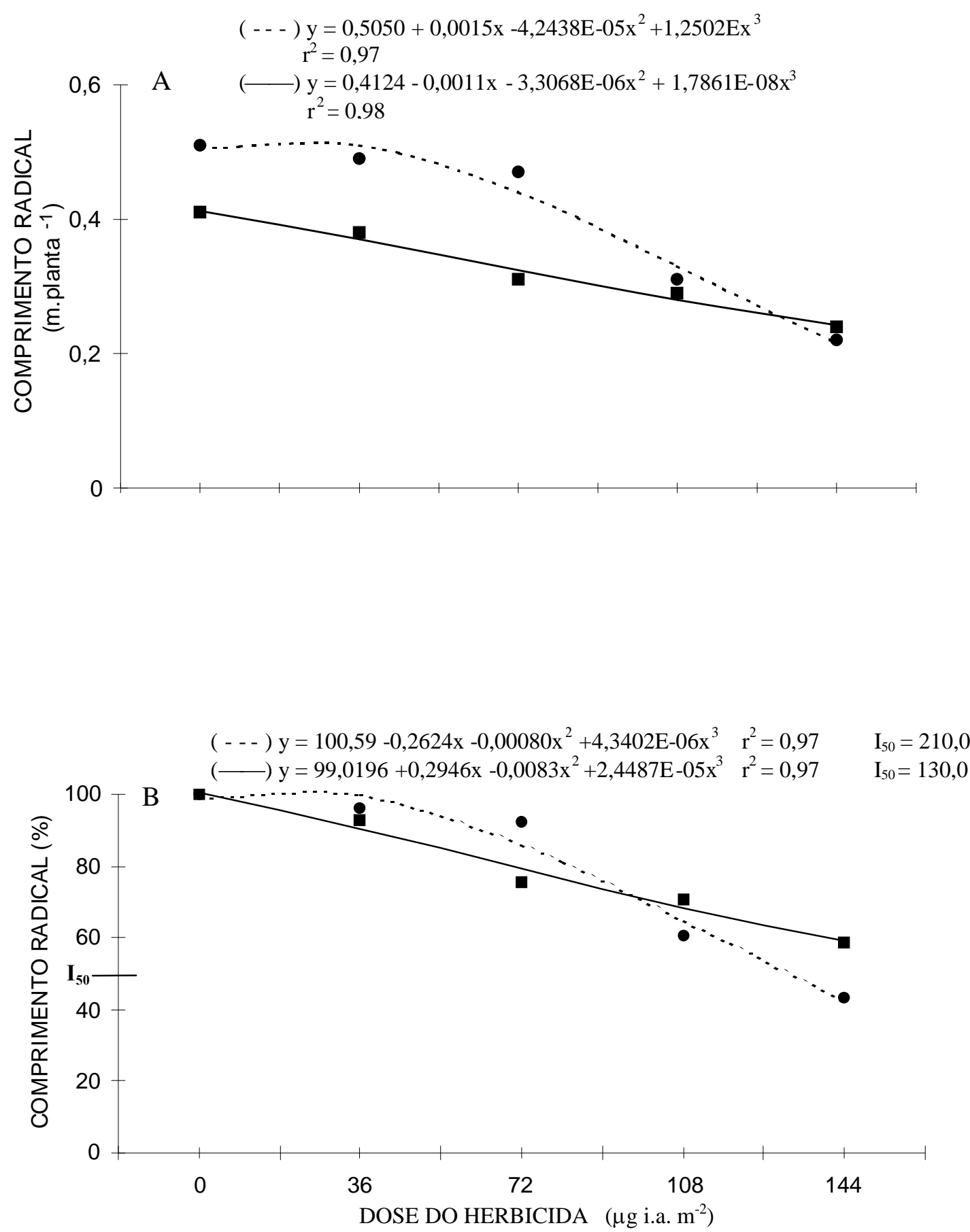

FIGURA 5. Comprimento radicular de plantas de soja em função de doses de sulfentrazone, aos 58 ( ) e aos 65 ( e - - - ) dias após a semeadura. 

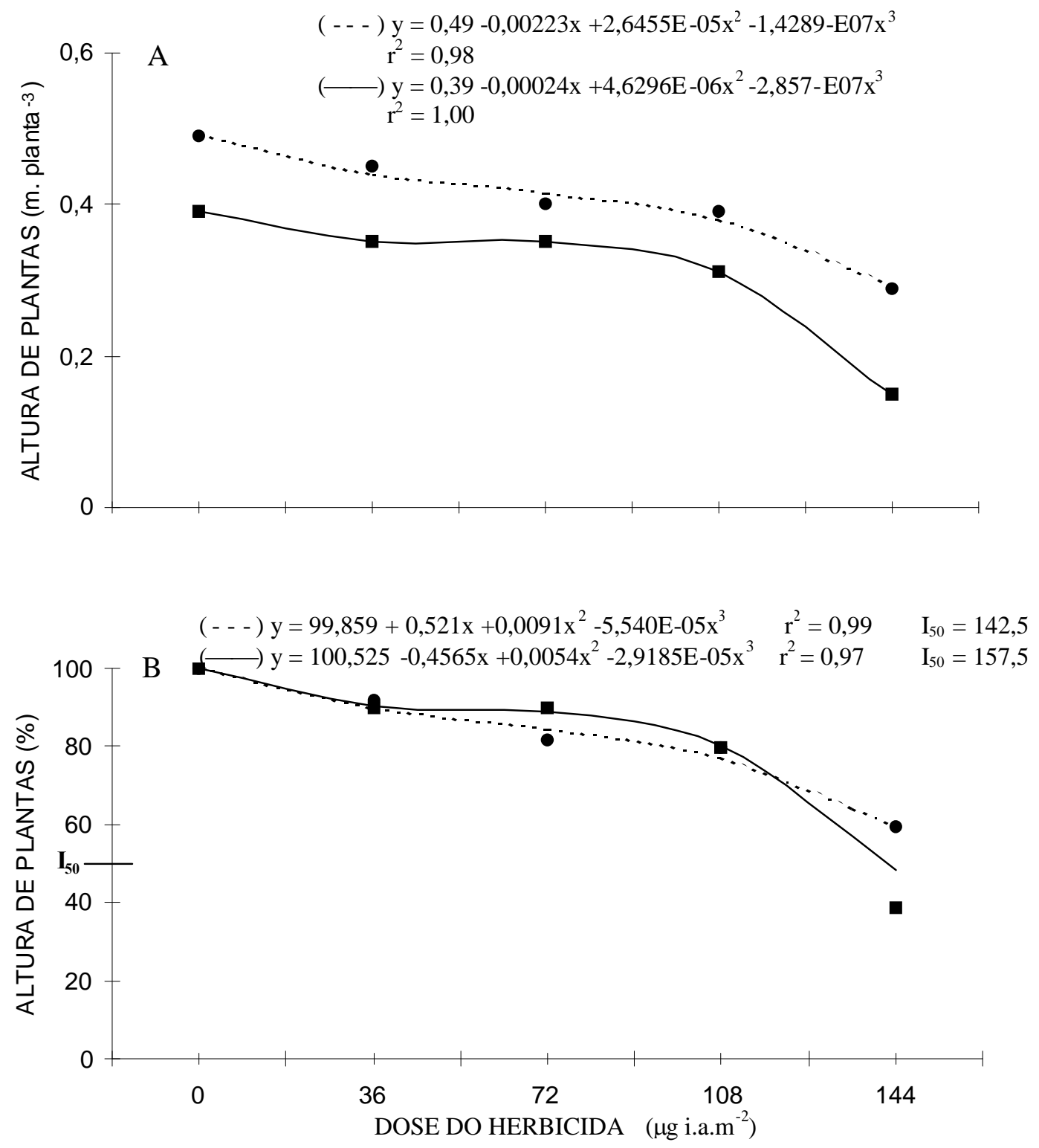

FIGURA 6. Altura de plantas de soja em função de doses de sulfetrazone, aos 58 65 (• e - - - ) dias após a semeadura.

O herbicida sulfentrazone em doses altas foi bastante prejudicial a cultura da soja, reduzindo fortemente $A_{f}$ nos estádios $\left(R_{3}\right.$ e $\left.R_{5}\right)$ da cultura. Nesses estádios ocorrem a expansão e formação das vagens e também o início do desenvolvimento das sementes que são drenos metabólicos preferenciais com grande demanda por fotoassimilados. Assim, justamente na fase em que a maquinaria fotossintética deveria ser a maior possível para produção de carboidratos, de modo a suprir a alta demanda dos órgãos reprodutivos, esta foi reduzida pela ação do herbicida.

O sulfentrazone produziu uma significativa redução na matéria seca das raízes (Wr), em ambos os estádios de crescimento, 
acentuando-se com o incremento da dose do herbicida (Figura 2A). A tendência de declínio em $\mathrm{Wr}$ em função da dose de sulfentrazone foi idêntica nos dois estádios de crescimento $\left(R_{3}\right.$ e $\left.R_{5}\right)$ avaliados. Comparando $\mathrm{Wr}$ das plantas controle, cujo valores foram de 2,13 e 2,86g. planta $^{-1}$, com os das plantas tratadas com $72 \mu \mathrm{g}$ i.a. $\mathrm{m}^{-2}$, com 0,77 e $1,31 \mathrm{~g} \cdot$ planta $^{-1}$, constatou-se uma redução em $\mathrm{Wr}$ de $63,8 \%\left(\mathrm{R}_{3}\right)$ e de $54,3 \%\left(\mathrm{R}_{5}\right)$.

Os $\mathrm{I}_{50}$ para $\mathrm{Wr}$ foram atingidos nas doses

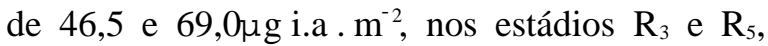
respectivamente. Nota-se que os $\mathrm{I}_{50}$ foram abaixo e próximo da dose recomendada, aos 58 e 65 DAS, respectivamente (Figura 2B). Provavelmente, houve uma recuperação dos efeitos negativos causados pelo sulfentrazone em Wr, no estádio $\mathrm{R}_{5}$.

A matéria seca da parte aérea (Wpa) da soja foi afetada negativamente pelo sulfentrazone, ocorrendo uma diminuição de Wpa em função do incremento de doses do herbicida tanto no estádio de crescimento $R_{3}$ quanto no $R_{5}$ (Figura $3 A$ ). Provavelmente, essa redução ocorre de forma direta por alocar menor quantidade de assimilados nos caules e folhas, em virtude da diminuição da taxa fotossintética ocasionada pela redução no tamanho do aparelho assimilatório $\left(\mathrm{A}_{\mathrm{f}}\right)$.

O índice que inibiu $50 \%$ da matéria seca da parte aérea $\left(\mathrm{I}_{50}\right)$ aos 58 DAS foi de $61 \mu \mathrm{g}$ i.a . ${ }^{-}$ ${ }^{2}$, já aos 65 DAS necessitou de uma dose maior para atingir o $I_{50}$, que foi de $124 \mu$ gi.a. $\mathrm{m}^{-2}$, demonstrando que o sulfentrazone produziu maior dano aos 58 do que aos 65 DAS (Figura 3B). Esses resultados estão de acordo com as pesquisa realizada com plantas de soja tratadas com sulfentrazone (Walker et al., 1992; Vidrine et al., 1994).

A matéria seca total da soja foi afetada negativamente pelo sulfentrazone, ocorrendo uma diminuição em função do incremento de doses do herbicida tanto no estádio de crescimento $R_{3}$ quanto no $\mathrm{R}_{5}$ (Figura $4 \mathrm{~A}$ ). A matéria seca total das plantas de soja foi severamente afetada pelo sulfentrazone, apresentando um $\mathrm{I}_{50}$ de $56 \mu$ g i.a. $\mathrm{m}^{-2}$ aos 58 DAS, dose abaixo da dose recomendada de sulfentrazone para a cultura da soja (Figura 4B). As matérias secas das plantas controle foram de 5,52 e 5,96g . planta $^{-1}$ enquanto as tratadas com $72 \mu \mathrm{g}$ i.a. m ${ }^{-2}$ apresentaram valores de 2,47 e $4,00 \mathrm{~g}$. planta $^{-1}$, mostrando uma redução de 55,2 e 32,8\%, nos estádios $R_{3}$ e $R_{5}$, respectivamente.

O comprimento do sistema radical das plantas de soja foi influenciado negativamente pelo herbicida sulfentrazone, mostrando uma diminuição do comprimento das raízes em função do incremento de doses do sulfentrazone, tanto no estádio $\mathrm{R}_{3}$ quanto no $\mathrm{R}_{5}$ (Figura $5 \mathrm{~A}$ ). Comparou-se o comprimento das raízes das plantas controles, cujo valores foram de 0,50 e $0,41 \mathrm{~m}$. planta $^{-1}$ respectivamente, aos 58 e 65 DAS, com as plantas tratadas com a dose de $72 \mu \mathrm{g}$ i.a. $\mathrm{m}^{-2}$, verificou-se que houve uma redução de 22 e $12 \%$. Na dose $144 \mu \mathrm{g}$ i.a. $\mathrm{m}^{-2}$ produziu uma redução similar para as duas épocas, sendo o comprimento médio das raízes de 0,28 e $0,22 \mathrm{~m}$. planta $^{-1}$.

As doses que inibiram $50 \%$ do comprimento radical $\left(\mathrm{I}_{50}\right)$ foram $130 \mu \mathrm{g}$ i.a. $\mathrm{m}^{-2}$ aos 58 DAS e superior $144 \mu$ gi.a. $\mathrm{m}^{-2}$ aos 65 DAS (Figura 5B), essas doses ficaram bem acima da dose de recomendada. Esses resultados foram semelhantes a pesquisa realizada com planta de Cassia ocidentalis tratadas com sulfentrazone (Dayan et al., 1996).

A altura das plantas de soja foi reduzida pelo herbicida sulfentrazone, ocorrendo uma diminuição na altura em função do incremento de doses do herbicida, tanto no estádio $\mathrm{R}_{3}$ quanto no $\mathrm{R}_{5}$ (Figura 6A). Quando comparado as alturas das plantas controle, cujo valores foram de $0,39 \mathrm{e}$ $0,49 \mathrm{~m}$. planta $^{-1}$, com as plantas tratadas na dose de $72 \mu \mathrm{g}$ i.a. $\mathrm{m}^{-2}$ do herbicida sulfentrazone, que foi de 0,35 e $0,42 \mathrm{~m}$. planta $^{-1}$, verificou-se que houve uma redução de 10,2 e 14,0\%, aos 58 e 65 DAS, respectivamente. Aparentemente essa redução causada na altura pela dose recomendada não foi acentuada, entretanto a dose de $144 \mu \mathrm{g}$ i.a m $^{-2}$ causou uma redução mais drástica na altura das plantas de soja de 0,15 e $0,29 \mathrm{~m}$. planta $^{-1}$, ocasionando uma redução de 
61,5 e 41,0\%, nos estádios $R_{3}$ e $\quad R_{5}$, respectivamente.

As doses que inibiram $50 \%$ na altura das plantas $\left(\mathrm{I}_{50}\right)$ foram elevadas, ou seja, maior do que $144 \mu$ g i.a $\cdot \mathrm{m}^{-2}\left(58\right.$ DAS) e $142,5 \mu \mathrm{g}$ i.a $\cdot \mathrm{m}^{-2}(65$ DAS) ( Figura 6B), ficando muito acima da dose recomendada.

A redução da matéria seca do sistema radical foi maior do que a matéria seca da parte aérea, quando comparada com as plantas controle e com o tratamento que recebeu a dose de $72 \mu \mathrm{g}$ i.a. $\mathrm{m}^{-2}$, dose recomendada, verifica-se que houve uma redução de $51,54 \%$ em $R_{3}$ e $31,72 \%$ em $\mathrm{R}_{5}$ na parte aérea e de $65,63 \%$ em $\mathrm{R}_{3} \mathrm{e}$ de $61,53 \%$ em $\mathrm{R}_{5}$ do sistema radical.

A relação parte aérea e sistema radical (PA/SR) das plantas de soja (Tabela 2) aumentou com incremento de doses de sulfentrazone nos estádios $R_{3}$ e $R_{5}$, em virtude da maior redução de matéria seca do sistema radical do que a parte aérea. A planta quando sofre um estresse causado por qualquer fator externo que atue na parte aérea, ocasionando redução na área e no metabolismo foliar, normalmente a injúria é mais acentuada nas raízes. A planta tenta se reorganizar, corrigindo os processos interfiridos na parte aérea, ficando o sistema radical prejudicado em virtude da maior retenção de açucares na parte aérea.

TABELA 2. Matéria seca da parte aérea (Wpa), das raízes (Wr) e a relação da parte aérea e sistema radical (PA/SR) aos 58 e 65 dias após a semeadura (DAS).

\begin{tabular}{|c|c|c|c|c|c|c|}
\hline \multirow{2}{*}{$\begin{array}{l}\text { DOSES } \\
\left(\mu \mathrm{g} \text { i.a } \cdot \mathrm{m}^{-2}\right)\end{array}$} & \multicolumn{2}{|c|}{ Wpa } & \multicolumn{2}{|c|}{$\mathrm{Wr}$} & \multicolumn{2}{|c|}{ PA/SR } \\
\hline & $\mathrm{R}_{3}$ & $\mathrm{R}_{5}$ & $\mathrm{R}_{3}$ & $\mathrm{R}_{5}$ & $\mathrm{R}_{3}$ & $\mathrm{R}_{5}$ \\
\hline 0 & $5,82 \mathrm{~A}$ & $5,83 \mathrm{~A}$ & $2,27 \mathrm{~A}$ & $2,73 \mathrm{~A}$ & 2,56 & 2,14 \\
\hline 36 & $3,15 \mathrm{~B}$ & $5,21 \mathrm{~A}$ & $1,05 \mathrm{~B}$ & $2,32 \mathrm{~A}$ & 3,00 & 2,14 \\
\hline 72 & $2,82 \mathrm{BC}$ & $3,98 \mathrm{~B}$ & $0,78 \mathrm{C}$ & $1,05 \mathrm{~B}$ & 3,61 & 3,79 \\
\hline 108 & $2,15 \mathrm{BC}$ & $2,95 \mathrm{C}$ & $0,77 \mathrm{C}$ & $0,94 \mathrm{~B}$ & 2,79 & 3,13 \\
\hline 144 & $1,22 \mathrm{C}$ & $2,65 \mathrm{C}$ & $0,38 \mathrm{D}$ & $0,90 \mathrm{~B}$ & 3,21 & 2,94 \\
\hline
\end{tabular}

* As médias seguidas por letras maiúsculas distintas diferem estatisticamente entre si ao nível de ( $\mathrm{p} \leq 0,05$ ), pelo teste de Duncan, na coluna.

\section{LITERATURA CITADA}

DAYAN, E.F.; WEETE, D.J.; HANCOCK, H. G. Differential sensitivity to sulfentrazone by sicklepod (Senna obtusifolia) and coffee senna (Cassia ocidentalis). Weed Sci., v.44, n. 1, p.12-17, 1996.

DAYAN, E. F.; DUKE, O. S.; REDDY, K. N.; HAMPER B. C.; LESCHINSKY, K. L.
Effects of isoxalizoles on protoporphyrinogen oxidase and porphyrin physiology. J. Agric. Food Chem., v. 52, n. 5, p. 967-975, 1997.

EL NAGGAR, S. F.; CREEKMORE, R. W.; SCHOKEN, M. J.; ROSEN, R. T.; ROBINSON, R. A. Metabolism of clomazone herbicide in soybean. J. Agric. Food Chem., v. 40, p. 880-883, 1992. 
FINCK, B. F. \& KUNERT, K. J. Vitamins C and E: an antioxidative system against herbicideinduced lipid peroxidation in higher plants. J. Agric. Food Chem. v. 33, p. 574 - 577, 1985.

GIFFORD,R.M.; TORNE， J.H; HITZ,W.D.; GIANQUINTA, R.T. Productivity and photoassimilate partitioning. Plant Physiol., v. 32, p. 485- 509, 1981.

VIDRINE, P.R.; JORDAN, D.L.; GIRLINGHOUSE,
M. J. Efficacy of F-6285 in soybean. Proc. South. Weed Sci. Soc., v. 47, p. 62, 1994.

WALKER, R. H.; RICHBURG, J. S.; JONES, R. E. F6285 efficacy as affected by rate and method of application. Proc. South. Weed Sci. Soc., v. 45, p. 51, 1992.

WAX, L.M. Weed control. In: CALDWEEL, B.E. (ed.). Soybean improvement production and uses. Amer. Soc. Agron., Madison, 1973. p.417-457. 